\title{
A location-allocation model for influenza pandemic outbreaks: A case study in India
}

\author{
Yashoda Devi $^{1}$. Sabyasachi Patra ${ }^{1}$ Surya Prakash Singh ${ }^{2}(\mathbb{C}$
}

Received: 22 April 2021 / Revised: 15 September 2021 / Accepted: 16 September 2021 / Published online: 24 September 2021

(c) The Author(s), under exclusive licence to Springer Science+Business Media, LLC, part of Springer Nature 2021

\begin{abstract}
Previous pandemics in 1918, 1957, 1968, and the ongoing COVID-19 pandemic have provided sufficient evidence of health concerns caused by influenza pandemics. The existing health care system is overwhelmed by the surging demand of susceptible and infected individuals due to the COVID-19 outbreak. It is crucial to identify and isolate infected individuals to prevent pandemic spread. Thus, a mixed-integer linear programming model is proposed in this study for the locationallocation of health care facility networks (i.e., temporary testing laboratories). The objective of this study is to ensure that test samples from various geographical locations reach testing laboratories as soon as possible and at minimum cost to ensure timely testing. Hence, the proposed model has two objectives: (i) minimization of the total cost and (ii) minimization of the maximum travel time from a patient node to a testing facility. Furthermore, to prevent capacity underutilization, the capacity of temporary testing laboratories is tailored in the model. A case study in Maharashtra, India, is used to demonstrate the real-life applicability of the proposed model. The study results has interesting implications for decision- and policy-makers.
\end{abstract}

Keywords Healthcare facility location $\cdot$ Mixed-integer linear programming $\cdot$ Pandemic outbreak $\cdot$ Healthcare in developing countries

\section{Introduction}

Pandemic outbreaks, whether driven by natural calamities or bioterrorism, have posed a threat to human lives and economic progress (Liu et al. 2020). There were three major influenza pandemics in the twentieth century: the Spanish flu (1918), Asian flu (1957), and Hong Kong flu (1968) (Ekici et al. 2014). Among these three pandemics, the Spanish flu had the highest impact, leading to 40-50 million deaths worldwide (Sun et al. 2014). Other examples of recent pandemics include the H5N1 outbreak in 2003 and the H1N1 outbreak in 2009, which affected millions of people worldwide (Liu et al. 2020). The recent coronavirus or COVID-19 pandemic has been the first global pandemic since the 1918 Spanish flu (Sodhi et al. 2021). The COVID-19 pandemic

Surya Prakash Singh

surya.singh@gmail.com

1 Operations Management \& Decision Sciences, Indian Institute of Management Kashipur, Udham Singh Nagar, Kashipur, Uttarakhand 244713, India

2 Department of Management Studies, Indian Institute of Technology Delhi, Delhi, India was first reported in Wuhan, China and has had a devastating impact on people's lives (Queiroz et al. 2020). The COVID-19 pandemic claimed 3.8 million lives and infected approximately 176 million people as of May 2021 (Koshta et al. 2021).

COVID-19 is a contagious disease spread by saliva droplets suspended in the air when an infected person coughs or sneezes (Mangili and Gendreau 2005). The virus can also survive for hours on metal surfaces and spread to those who come in contact with these surfaces (Koshta et al. 2021). The risk of virus spread is higher in crowded places and when people move from an infected area to another place, necessitating increased monitoring and planning activities (Lam et al. 2011; Chowdhury et al. 2020). To break the COVID-19 transmission chain, countries worldwide have suspended all economic and noneconomic activities and gone into complete lockdowns (Chakraborty and Maity 2020; Qin et al. 2021). The WHO (2020) has recommended several COVID19 preparedness practices, including regular handwashing, social distancing, and avoiding unnecessary travel. However, an effective and efficient health care system is also critically needed. A healthcare system enables infected patients to be quickly identified, such that these patients can be separated 
from others and treated, thereby preventing the spread of disease.

Operations and supply chain management (OSCM) scholars have been quick to respond to the disruption caused by COVID-19 by publishing articles to provide support to decision-makers, policy-makers, and researchers. For example, Aldrighetti et al. (2021), Ivanov and Dolgui (2021a, b), Queiroz et al. (2020), and Sodhi et al. (2021) provided guidance to researchers on disruption risk modeling, methods to cope with the ripple effect, guidance on resilience assessment and viability analysis, strategies that commercial supply chains could use to cope with the pandemic, and ways to improve the responsiveness of supply chains for essential products, respectively. Paul and Chowdhury (2020) proposed a mathematical model for supply chains for essential products to manage disruptions. Ivanov (2021) proposed four adaptive strategies to maintain supply chain viability during a pandemic outbreak using a mixed-method approach. However, the health care supply chain, which is at the forefront of the fight against COVID-19, is equally important and has not received sufficient attention from OSCM scholars.

Although measures such as lockdowns and social distancing are important to confine the spread of COVID-19, it is equally important to have an effective health care system to facilitate widespread testing (Araz et al. 2020). The appropriate location of testing infrastructure or laboratories is crucial to ensure that test samples are transported quickly from any geographical location to testing laboratories (Koshta et al. 2021). Thus, appropriate location of testing laboratories facilitates timely identification and isolation of infected individuals, ultimately reducing pandemic spread. Furthermore, testing laboratories should be located outside hospitals to prevent overcrowding and the possibility of transmission to other patients and health care workers (Salathé et al. 2020); hence, such testing laboratories are referred to as temporary testing laboratories (TTLs) in this paper. The aim of this study is to develop a mathematical model for locating a temporary testing laboratory (TTL) and the allocation of demand thereof. The following research questions are proposed in light of the discussion presented above.

RQ1. How can a network of temporary testing laboratories be developed for timely testing during a pandemic?

RQ2. How can temporary testing laboratories be located and demand be allocated during an influenza pandemic outbreak?

RQ3. How can equity of services to demand locations be ensured?

A response model is proposed in this study to determine the locations of temporary testing laboratories (TTLs) to escalate the testing rate during an influenza pandemic outbreak. The proposed location-allocation model has two objectives: i) minimization of cost and ii) minimization of the maximum travel time. The cost components include the fixed cost, variable or operating cost, transportation cost, and capacity underutilization cost. The minimization of the maximum travel time is used as an objective to ensure that no customer location is prohibitively far from a TTL, which could delay testing due to the long time spent transporting test samples. Furthermore, scholars suggest that capacity underutilization can result in extra costs due to resource wastage (Blackmon et al. 2021). Therefore, the model is updated to address capacity underutilization.

In summary, the problem is solved in two steps. First, a mathematical model is proposed to establish TTLs with predetermined capacities to provide equity of service at minimum cost. Second, the model is modified by incorporating capacity as a decision variable to prevent capacity underutilization. Finally, the model is solved for a case study in Maharashtra during the COVID-19 pandemic. The case details are discussed later in the paper.

The remainder of this study is organized as follows: a literature review is presented in Sect. 2. The problem is described in Sect. 3, along with the study assumptions and the mathematical model. In Sect. 4, numerical experiments and a modification of the mathematical model are presented. In Sect. 5, we present a case study in Maharashtra, India, describe the case information in detail and illustrate the application of the proposed model. The model results are also reported and discussed. The implications of the study are discussed in Sect. 6. Finally, conclusions and future directions are presented in Sect. 7.

\section{Background}

\subsection{Literature review}

The COVID-19 pandemic has had a dynamic and severe impact on people's lives due to the contagious nature of the disease (Koshta et al. 2021). Thus, the location of TTLs is critical for reducing the spread of the pandemic by providing timely testing and ensuring equity of services at various geographical locations. Hence, three research directions are followed in the present study: (1) OSCM during the COVID-19 outbreak, (2) health care facility location during a pandemic or epidemic outbreak, and (3) health care facility location to ensure equity or fairness of services.

\subsubsection{OSCM during COVID-19}

The tremendous challenges posed by COVID-19 have exposed the vulnerability of supply chains. These chains have been faced with and struggled to manage both 
supply- and demand-side disruptions. OSCM scholars proposed various strategies for decision-makers to respond to the disruption caused by the COVID-19 pandemic. For example, Blackmon et al. (2021) developed a decision support system to assist the Los Angeles Regional Food Bank in alleviating food insecurity during the COVID-19 outbreak. Ivanov (2021) predicted the impact of COVID-19 on global supply chain performance and reported that the timing of opening and closing facilities at different echelons is the most important predictor of supply-chain performance. Paul and Chowdhury (2020) proposed a production recovery plan for supply chains of essential or high-demand products using a mathematical modeling approach. Based on the tenets of organizational information processing theory and a resourcebased view, Baz and Ruel (2021) reported that supply-chain risk management is crucial for absorbing disruptions and improving the resilience and robustness of supply chains.

In the context of health care planning during the COVID19 outbreak, Oeser and Romano (2021) examined risk pooling using the survey method. These authors suggested that risk pooling could substantially reduce economic loss while maintaining service levels during the outbreak. Tirkolaee et al. (2021) proposed a mixed-integer linear programming location-routing problem with time windows for COVID-19 medical waste management. Zeferino et al. (2021) prioritized the factors that influence site-selection decisions for the location of quarantine centers for COVID-19 patients using the analytical hierarchy process (AHP) and Pareto techniques. The authors reported the safety of quarantine facilities as the most important factor, followed by skilled workforce availability. Finally, Risanger et al. (2021) proposed an optimization model for increasing coverage of COVID-19-related health care services in the United States. The aim of the study was to choose pharmacies to provide COVID-19 testing (or COVID-19 sample collection) by maximizing people's ability to travel to the nearest pharmacy.

\subsubsection{Healthcare facility location during pandemic or epidemic outbreak}

Health care planning during pandemic or epidemic outbreaks has received significant attention from OSCM scholars in the past (Sun et al. 2014). Scholars have proposed facility location models for various types of health care facilities during pandemic or epidemic outbreaks. Lee et al. (2009) investigated the optimal location of point-ofdistribution sites for mass prophylaxis during an anthrax attack in a metropolitan area. The model was also used to allocate and determine the number of health personnel needed to manage the established facilities. Büyüktahtakın et al. (2018) proposed a spatio-temporal mixed-integer programming model to locate Ebola treatment centers (ETCs).
The allocation of a limited budget over a multiperiod planning horizon to control the effects of the Ebola outbreak in West Africa was investigated.

Liu et al. (2020) modified this model for the 2009 H1N1 pandemic by changing the capacity constraints and applied the modified model to China as a case study. The authors developed a mixed-integer nonlinear programming model (MINLP) and determined when isolation wards should be opened and closed when not in use. In a recent study, Anparasan and Lejeune (2019) proposed an integer linear programming model for locating treatment facilities in Haiti in response to the 2010 cholera outbreak. The model maximizes the number of adversely affected people transported from a triage point to treatment facilities. Additionally, the allocation of health care staff and ambulances to the triage point was considered in the model.

\subsubsection{Healthcare facility location for equity or fairness of services}

Another theme in the extant literature that is closely related to the present study is equity or fairness of services. Equity or fairness refers to equal access of resources at all demand points, irrespective of geographical location (RodríguezEspíndola et al. 2018). Beheshtifar and Alimoahmmadi (2015) proposed a multiobjective location-allocation model for new clinics to improve health care services. The optimal location of clinics was determined by considering four objectives: (1) minimization of land acquisition and clinic establishment costs, (2) minimization of land-use incompatibility, (3) minimization of inequity in access to facilities, and (4) minimization of the total travel cost. The authors defined equity as the reduction of variation in the access distance to a clinic. Núñez Ares et al. (2016) proposed a mathematical model for the location of a fixed number of roadside wellness centers in Sub-Saharan Africa by maximizing the number of patients covered and ensuring continuity of access along routes to the centers. The authors modeled equity considering continuity of access to health services for longdistance truck drivers in Sub-Saharan Africa.

Similarly, Rodríguez-Espíndola et al. (2018) developed a multiobjective model for the location of emergency health care, shelter, and distribution centers and the allocation of resources to provide relief to disaster victims. The authors tested the model using the Mexico flood of 2013 as a case study. The objective minimizes the maximum unfulfillment of products and services across all shelters and serves as a measure of equity or fairness among demand points. In a recent study, Nasrabadi et al. (2020) explored a real-world issue encountered at public health care facilities in Semnan Province, Iran. The problem was defined as the location of health care facilities with improved customer access at minimum cost. A model was developed to make decisions 
on the allocation of service units and the capacity of health care facilities.

\subsection{Research gaps and study contributions}

The review of the extant literature shows that OSCM scholars have primarily worked on strengthening commercial supply chains. However, no studies performed at the intersection of COVID-19 and the health care supply chain have determined TTL locations to reduce the transportation time of COVID-19 test samples from sample collection centers to TTLs. As explained earlier, reducing the transportation time facilitates the timely testing and identification of infected individuals, ultimately helping to reduce the spread of COVID-19.

In the context of past pandemics or epidemics, scholars have proposed facility location models for various types of health care facilities, such as treatment and point-ofdistribution facilities, to carry out relief operations. However, to the best of our knowledge, the location of TTLs has not been studied in the past. The location of TTLs is vital within the considered context because of the contagious nature of COVID-19. The ability of the COVID-19 virus to spread through the air and on material surfaces makes it important to establish testing laboratories outside existing health facilities to prevent cross-contamination (Koshta et al. 2021).

Despite the importance of equity or fairness in health care services, the concept of equity has received little attention from OSCM scholars (as mentioned in Sect. 2.1.3). Given the contagious nature of COVID-19 and its negative impact on human health, all members of the population must be treated equally during these challenging times. Another reason for ensuring equity is that any neglected geographical location can become a hub for virus spread. As a result, the objective of a virus-free society will not be achieved. Therefore, equity also helps to create a win-win situation for all. In the present study, we achieve equity by effectively locating TTLs, i.e., minimizing the maximum travel time between any geographical location or demand node and a TTL.

\section{Problem definition and model formulation}

\subsection{Problem definition}

The problem considered in the present study is one faced by decision- and policy-makers, that is, the identification of locations for health care facilities, especially TTLs, during a pandemic outbreak. A pandemic or epidemic is a large-scale emergency that occurs unexpectedly with low frequencies and lasts several months. Testing, isolation, and contact tracing of suspects are the backbone of the response phase to curb escalation of virus transmission. However, geographic differences and limited numbers of health care facilities can considerably increase the time required to reach designated health care facilities and can likely affect testing, as has been evident during the COVID-19 pandemic. As per the Centre of Disease Control (2021) guidelines, COVID-19 test samples should reach a testing lab as soon as possible. Hence, timely test sample delivery can be achieved by locating a testing facility close to a demand point/node. In the present study, a mixed-integer linear programming model for the location of TTLs during the pandemic outbreak is proposed to ensure equity of service at minimum cost. The proposed bi-objective mixed-integer programming model simultaneously minimizes the cost of TTL location and minimizes the maximum travel time between the TTL and demand nodes. The model can also be used to determine the capacity of TTLs to ensure full capacity utilization and avoid resource wastage. The proposed model is detailed in the following section.

\subsection{Assumptions}

The following assumptions are made in this study and are consistent with the literature and practical observations.

- Potential facility locations for the TTLs are known, which is in line with the literature (Nasrabadi et al. 2020).

- An arborescent network is considered within which each TTL can serve multiple patient demands, but the converse is not allowed (Chowdhury et al. 2017). This assumption is valid within the considered context because samples from demand nodes are sent to the nearest TTL to ensure timely testing. Hence, the demand of a node is assigned to only one TTL.

- We consider a particular region's demand/test samples to be concentrated at one point, referred to as the demand node. Hence, the samples collected at various locations are moved to a hub (demand node) with a known location. The samples from the hub are subsequently delivered to the assigned TTL. This assumption is commonly made in facility location problems.

- The cost of transporting test samples from a demand node to a TTL (the transportation cost) is considered to be a linear function of the distance traveled from the demand node to the potential TTL location, i.e., the larger the distance is, the higher the cost is. Therefore, the transportation cost increases with the distance between nodes.

- TTLs are capacitated in nature. This assumption is valid because various reasons make it practically impossible for a facility to have unlimited capacity. For example, unlimited space is required to produce or store an unlimited quantity of products to serve demand. Moreover, capacity is used as the decision variable in the updated 
model to determine the capacity of a TTL. Capacity determination circumvents the problem of underutilization, as shown in the following section.

\subsection{Model formulation}

In this section, the notations and symbols used in the model formulation are presented (Table 1), followed by a description of the mathematical model.

In the present study, the location of TTLs are selected from a set of potential locations $J$ to cater to a set of demand nodes $I$. The study considers two objectives. The first objective minimizes the total cost, including costs for fixed facility opening, operation, capacity underutilization, and transportation. The second objective minimizes the maximum travel time between any demand node $i$ and a TTL $j$. In the present study, the travel time $T_{i j}$ is considered a linear function of the distance $D_{i j}$, i.e., $\left(T_{i j}=D_{i j}+\beta\right)$. Hence, the time required to travel $60 \mathrm{~km}$ equals $(60+\beta)$ minutes. Here, $\beta$ represents the time consumed in other activities, such as the loading and unloading of samples. We take the value of $\beta$ to be $60 \mathrm{~min}$.

\section{Objective 1: Minimize}

$$
\begin{aligned}
\left(\sum_{j \in J} F_{j} y_{j}+\sum_{i \in I} \sum_{j \in J} Q_{i} * O_{j} * y_{j}\right. & +\sum_{i \in I} \sum_{j \in J}\left(H_{j}-Q_{i}\right) * C_{j} * y_{j} \\
& \left.+\sum_{j \in J} \sum_{i \in I} z_{i j} * M * D_{i j}\right)
\end{aligned}
$$

\section{Objective 2:}

Min $X$

Subject to:

$$
\sum_{j \in N} z_{i j}=1 \quad \forall i \in N
$$

$z_{i j} \leq y_{j} \quad \forall i \in N, j \in N$

$\sum_{i \in I} Q_{i} z_{i j} \leq y_{j} H_{j} \quad \forall j \in N$

$\sum_{j \in J} y_{j} \leq P$

$X \geq \sum_{j \in J} T_{i j} * z_{i j} \quad \forall i \in N$

$y_{j} \in\{0,1\} \quad \forall i \in N, j \in N$

$z_{i j} \in\{0,1\} \quad \forall i \in N, j \in N$

The first objective function (1) minimizes the total cost. The first term in Eq. (1) represents the fixed cost for opening TTLs, including rent, labor, and equipment costs. The second term is the operating or variable cost of TTLs.

\begin{tabular}{|c|c|}
\hline \multicolumn{2}{|c|}{ List of sets and indices } \\
\hline$N$ & Set of all nodes in the network $(I, J)$ \\
\hline$I$ & Set of demand nodes, $I=\{i \mid i \epsilon(1,2,3 \ldots . m)\}$, indexed by $i$ \\
\hline$J$ & Set of potential facility locations, $J=\{j \mid j \epsilon(1,2,3 \ldots$ n) $\}$, indexed by $j$ \\
\hline \multicolumn{2}{|c|}{ Parameters } \\
\hline$F_{j}$ & Fixed cost of opening a facility at node $j$ \\
\hline$O_{j}$ & Operating cost of the facility at node $j$ \\
\hline$C_{j}$ & Non-operating cost of TTL (underutilization cost) \\
\hline$H_{j}$ & The capacity of the facility at node $j$ \\
\hline$Q_{i}$ & Demand at customer node $i$ \\
\hline$M$ & Per unit transportation cost \\
\hline$D_{i j}$ & Distance between customer node $i$ and facility node $j$ \\
\hline$P$ & Total number of TTLs \\
\hline$T_{i j}$ & Travel time from demand node $i$ to facility location node $j$ \\
\hline$\beta$ & Variable time (time-consumed to load and unload the samples) \\
\hline \multicolumn{2}{|c|}{ Decision variables } \\
\hline \multirow[t]{2}{*}{$y_{j}$} & if the facility is located at node $\mathrm{j}$ \\
\hline & 0 if the facility is not located at node $\mathrm{j}$ \\
\hline \multirow[t]{2}{*}{$z_{i j}$} & $\{1$ if a customer node $\mathrm{i}$ is assigned to facility node $\mathrm{j}$ \\
\hline & ( 0 if a customer node $\mathrm{i}$ is not assigned to facility node $\mathrm{j}$ \\
\hline
\end{tabular}
The third term represents the capacity underutilization or

Table 1 Notations 
nonoperating cost. As the name suggests, underutilization costs are incurred when TTLs have unused capacity. Underutilization may occur when a facility is opened with predetermined capacity, but the assigned demand falls short of the facility's capacity. The underutilization cost is calculated by multiplying the per unit underutilization cost by the unused capacity. The final term in the first objective function is the transportation cost of collecting samples from demand nodes. Here, it is important to mention that the study does not consider vehicle routing for the collection of test samples. That is, a vehicle leaves the TTL, reaches a demand point, collects all the test samples (assuming that the vehicle has sufficient capacity to carry all the samples available at any demand node), and returns to the same TTL without traveling to any other demand node.

The second objective function (2) minimizes the maximum travel time between a TTL and a demand node. The maximum travel time between any TTL location $j$ and demand node $i$ is modeled using Eq. (7). The value for $X$ determined by using Eq. (7) is minimized using Eq. (2) to achieve the desired objective. The second objective function ensures equity or fairness of treatment at all demand nodes. Minimization of the maximum travel time between the locations of the TTL $j$ and demand node $i$ ensures that the facility will not be located excessively far from any demand node $i$. Therefore, the time to transport test samples to a TTL from a demand node is minimized, irrespective of the geographical location of the demand node.

Equations (3) to (9) represent the constraints on the proposed model. Equation (3) is an assignment constraint that ensures that a demand node $i$ is assigned to exactly one TTL. Constraint (4) ensures that the demand node $i$ is assigned to the potential facility location node $j$ if and only if the TTL has been opened at node $j$. Equation (5) is a capacity constraint on the TTLs, which ensures that the total demand assigned to a TTL at a potential facility location node $j$ is less than or equal to the TTL capacity. Constraint (6) ensures that the number of TTLs opened are less than or equal to a maximum allowed number. Constraint (7) sets the maximum travel time between the demand node $i$ and potential facility location node $j$. Finally, constraints (8) and (9) restrict the $y_{j}$ and $z_{i j}$ variables to take only binary values, i.e., $(0,1)$.

\section{Numerical experiment and model modification}

The proposed model (see Sect. 3.3) is solved using the benchmark instances of Holmberg et al. (1999). Specifically, the test $P 1$ instance for the capacitated single-source facility location problem is used in the present study. The test $P 1$ instance has 10 nodes, which are potential facility locations as well as demand nodes. The fixed, variable or operating, and capacity underutilization costs are 14,000 INR, 4000 INR, and 1000 INR, respectively. All costs in the manuscript are presented in INR, i.e., Indian currency/rupees. The proposed model is solved for three different values of $P$, i.e., $P=4, P=6$, and $P=9$.

The results of all three values of $P$ are presented in Tables 2, 3, and 4. These results show that when predefined capacity TTLs are opened, a portion of the capacity remains underutilized. This underutilized capacity may result in extra costs for decision- or policy-makers interested in establishing TTLs (Blackmon et al. 2021).

To eliminate capacity underutilization, the model proposed in Sect. 3.3 is modified. In the updated model, a new decision variable $S_{j}$ is introduced to determine the capacity of a facility opened at any node $j$. We assume that an additional cost is incurred for every opened unit to tailor the capacity of each TTL. Hence, a per-unit capacity tailoring cost $R$ is introduced into the model. The modified model is presented below.
Table 2 Results of facility location, demand allocation, and underutilized capacity for $P=4$

\begin{tabular}{lllllll}
\hline $\begin{array}{l}\text { Potential locations } \\
\text { of TTL }(\boldsymbol{j})\end{array}$ & $\begin{array}{l}\text { Opened } \\
\text { facility } \\
\left(\mathbf{y}_{\mathbf{j}}\right)\end{array}$ & $\begin{array}{l}\text { Capacity of } \\
\text { facility }\left(\mathbf{H}_{\mathbf{j}}\right)\end{array}$ & $\begin{array}{l}\text { Assigned } \\
\text { demand points } \\
\left(\mathbf{z}_{\mathbf{i j}}\right)\end{array}$ & Demand $\left(\mathbf{Q}_{\mathbf{i}}\right)$ & $\begin{array}{l}\text { Total } \\
\text { demand } \\
\text { served }\end{array}$ & $\begin{array}{l}\text { Underutilized } \\
\text { capacity }\end{array}$ \\
\hline 1 & 0 & 110 & 0 & 0 & 0 & 0 \\
2 & 1 & 110 & 1,2 & 49,29 & 78 & 32 \\
3 & 1 & 110 & $3,5,7,9$ & $23,18,48,15$ & 104 & 6 \\
4 & 0 & 110 & 0 & 0 & 0 & 0 \\
5 & 0 & 110 & 0 & 0 & 0 & 0 \\
6 & 0 & 110 & 0 & 0 & 0 & 0 \\
7 & 0 & 110 & 0 & 0 & 0 & 0 \\
8 & 1 & 110 & $4,6,8,10$ & $40,17,13,31$ & 101 & 9 \\
9 & 0 & 110 & 0 & 0 & 0 & 0 \\
10 & 0 & 110 & 0 & 0 & 0 & 0 \\
\hline
\end{tabular}

Objective function 1: $5.9047 \mathrm{e}+7$, Objective function 2: $260 \mathrm{~min}$, computational time: $0.37 \mathrm{~s}$ 
Table 3 Results of facility location, demand allocation, and underutilized capacity for $P=6$

\begin{tabular}{lllllll}
\hline $\begin{array}{l}\text { Potential loca- } \\
\text { tions of TTL }(\boldsymbol{j})\end{array}$ & $\begin{array}{l}\text { Opened } \\
\text { facility }\left(\boldsymbol{y}_{\boldsymbol{j}}\right)\end{array}$ & $\begin{array}{l}\text { Capacity of } \\
\text { facility }\left(\boldsymbol{H}_{\boldsymbol{j}}\right)\end{array}$ & $\begin{array}{l}\text { Assigned } \\
\text { demand point } \\
\left(z_{\boldsymbol{i j}}\right)\end{array}$ & Demand $\left(\boldsymbol{Q}_{\boldsymbol{i}}\right)$ & $\begin{array}{l}\text { Total } \\
\text { demand } \\
\text { served }\end{array}$ & $\begin{array}{l}\text { Underutilized } \\
\text { capacity }\end{array}$ \\
\hline 1 & 1 & 60 & 1 & 49 & 49 & 11 \\
2 & 1 & 60 & 2 & 29 & 29 & 31 \\
3 & 1 & 60 & $3,5,9$ & $23,18,15$ & 56 & 4 \\
4 & 1 & 60 & 4,6 & 40,17 & 57 & 3 \\
5 & 0 & 60 & 0 & 0 & 0 & 0 \\
6 & 0 & 60 & 0 & 0 & 0 & 0 \\
7 & 1 & 60 & 7 & 48 & 48 & 12 \\
8 & 1 & 60 & 8,10 & 13,31 & 44 & 16 \\
9 & 0 & 60 & 0 & 0 & 0 & 0 \\
10 & 0 & 60 & 0 & 0 & 0 & 0 \\
\hline
\end{tabular}

Objective 1: 8.7876e +6; Objective 2: $295 \mathrm{~min}$; computational time: $18.28 \mathrm{~s}$
New parameter:

$R=$ Per unit capacity cost of the facility.

New Decision variable:

$S_{j}=$ Capacity of facility node $\mathrm{j}$.

Modified objective 1: Minimize

$$
\begin{aligned}
\left(\sum_{j \in J} F_{j} y_{j}+\sum_{i \in I} \sum_{j \in J} Q_{i} * O_{j} * y_{j}\right. & +\sum_{i \in I} \sum_{j \in J} z_{i j} * M * D_{i j} \\
& \left.+\sum_{j \in J} S_{j} * R\right)
\end{aligned}
$$

objective 2: Eq. (2)

Subject to:

Equation (3), (4), (7) - (9)

$S_{j} \geq \sum_{i \in I} Q_{i} * z_{i j} \quad \forall j \in J$

$\sum_{j \in J} y_{j}=P$
The updated model is first solved using the Holmberg et al. (1999) benchmark instance for the aforementioned $P$ values. The results show that for all three cases, i.e., $P=4$, $P=6$, and $P=9$, there is no capacity underutilization (Table 5). These results demonstrate that the proposed model can ensure equity of services with minimum cost and no underutilized capacity. The model is applied to a case study in the following section.

\section{Case study}

A case study is presented in this section along with the data employed in the analysis. The results of applying the model to the case study and a sensitivity analysis are also presented.

\subsection{Case description}

The proposed model is tested using a case study in Maharashtra, India. India is chosen because it is the world's
Table 4 Results of facility location, demand allocation, and underutilized capacity for $P=9$

\begin{tabular}{lllllll}
\hline $\begin{array}{l}\text { Potential location } \\
\text { of TTL }(\boldsymbol{j})\end{array}$ & $\begin{array}{l}\text { Opened } \\
\text { facility } \\
\left(\boldsymbol{y}_{\boldsymbol{j}}\right)\end{array}$ & $\begin{array}{l}\text { Capacity of } \\
\text { facility }\left(\boldsymbol{H}_{\boldsymbol{j}}\right)\end{array}$ & $\begin{array}{l}\text { Assigned } \\
\text { demand points } \\
\left(\boldsymbol{z}_{\boldsymbol{i j}}\right)\end{array}$ & Demand $\left(\boldsymbol{Q}_{\boldsymbol{i}}\right)$ & $\begin{array}{l}\text { Total } \\
\text { demand } \\
\text { served }\end{array}$ & $\begin{array}{l}\text { Underutilized } \\
\text { capacity }\end{array}$ \\
\hline 1 & 1 & 50 & 1 & 49 & 49 & 1 \\
2 & 1 & 40 & 2 & 29 & 29 & 11 \\
3 & 0 & 40 & 0 & 0 & 0 & 0 \\
4 & 1 & 40 & 4 & 40 & 40 & 0 \\
5 & 1 & 40 & 5 & 18 & 18 & 22 \\
6 & 0 & 40 & 0 & 0 & 0 & 0 \\
7 & 1 & 50 & 7 & 48 & 48 & 2 \\
8 & 1 & 40 & 6,8 & 17,13 & 30 & 10 \\
9 & 1 & 40 & 3,9 & 23,15 & 38 & 2 \\
10 & 1 & 40 & 10 & 31 & 31 & 9 \\
\hline
\end{tabular}

Objective 1: 1.0308e + 7; Objective 2: $143 \mathrm{~min}$; computational time: $64 \mathrm{~s}$ 
Table 5 Solutions of the modified model

\begin{tabular}{lllll}
\hline Potential facility locations $(\boldsymbol{j})$ & $\begin{array}{l}\text { When P=4 } \\
\text { Opened TTL } \\
\text { with capacity } \\
\left(\boldsymbol{S}_{\boldsymbol{j}}\right)\end{array}$ & $\begin{array}{l}\text { When P=6 opened } \\
\text { TTL with capacity } \\
\left(\boldsymbol{S}_{\boldsymbol{j}}\right)\end{array}$ & $\begin{array}{l}\text { When P=9 opened } \\
\text { TTL with capacity } \\
\left(\boldsymbol{S}_{\boldsymbol{j}}\right)\end{array}$ & $\begin{array}{l}\text { Underutilized } \\
\text { capacity }\end{array}$ \\
\hline 1 & 49 & 49 & 49 & 0 \\
2 & 29 & 29 & 29 & 0 \\
3 & 104 & 104 & 0 & 0 \\
4 & 0 & 40 & 40 & 0 \\
5 & 0 & 0 & 18 & 0 \\
6 & 0 & 17 & 17 & 0 \\
7 & 0 & 0 & 71 & 0 \\
8 & 101 & 0 & 13 & 0 \\
9 & 0 & 0 & 15 & 0 \\
10 & 0 & 44 & 31 & 0 \\
Objective 1 & $5.019 \mathrm{e}+6$ & $7.3048 \mathrm{e}+6$ & $1.0739 \mathrm{e}+7$ & \\
Objective 2 & $167 \mathrm{~min}$ & $122 \mathrm{~min}$ & $28 \mathrm{~min}$ & \\
Computation-al time & $11 \mathrm{~s}$ & $12 \mathrm{~s}$ & $16 \mathrm{~s}$ & \\
\hline
\end{tabular}

second-largest populous country and has only 1.3 hospital beds for every 1000 people. During the initial phase of COVID-19, the country had approximately 52 testing laboratories (Tanne et al. 2020). As of 10 April 2020, 146 government laboratories and 67 private laboratories were designated by the Indian Council of Medical Research (ICMR) for COVID-19 testing (Meghana et al. 2021). However, an abrupt lockdown resulted in the mass exodus of 120 million individuals from cities to rural areas, transmitting the coronavirus and making the Indian health care system more fragile and fragmented (Meghana et al. 2021), highlighting the need to strengthen the health care system. Among Indian states, Maharashtra has had the highest number of COVID19 cases since the very beginning of the pandemic (https:// www.covid19india.org/; Kodge 2021). The state accounted for almost $21.25 \%$ of the total cases in the country (Kumar 2020). Moreover, Maharashtra has the country's most populated cities (Radhakrishnan et al. 2020). Therefore, the Pune division of Maharashtra is considered as a case study for analysis.

The Pune division is the largest of the six administrative divisions of Maharashtra (Banerjee 2018) and consists of five districts, namely, Pune, Solapur, Satara, Sangali and Kolhapur (IndiaNetZone 2017), and 58 subdistricts. The Pune division covers 57,275 square kilometers and has a population of 19,997,778 (Census 2011). Pune district has 14 subdistricts, Solapur and Satara each have 11 subdistricts, Sangali has ten subdistricts, and Kolhapur has 12 subdistricts. During the second wave of COVID-19, the Pune division reported the highest number of COVID-19 cases in Maharashtra and was among the worst affected regions in the entire country (Sinha 2021). Considering the severity of the situation in the Pune division, the proposed model provides insights into the effective location of TTLs in the subdistricts of this division. The subdistricts are considered potential facility location sites as well as demand nodes. Subdistrictlevel data are used to provide microlevel information that is otherwise overlooked by using district- or state-level data because of the size and population of India.

\subsection{Data}

The model has two major dataset requirements. The first is demand data or data for individuals suspected of having COVID-19, and the second is the data on the distances between subdistricts. The suspects are individuals who have been subjected to a COVID-19 test. Hence, these suspects constitute the demand to be met by all the TTLs. The total number of tested samples is not available, but the number of people who tested positive for COVID-19 have been published in a report by the Public Health care Department, Government of Maharashtra, India (https://www. covid19maharashtragov.in/mh-covid/dashboard). The report also states a positivity rate of approximately $15 \%$, i.e., of the total samples tested for COVID-19, 15\% are positive, and the rest are negative. The total number of people who tested positive for COVID-19 and the positivity rate are used to calculate the demand using Eq. 13.

Total number of samples tested by TTLs

$$
\begin{aligned}
& =(100 / \text { positivity rate }) \\
& \times \text { number of people tested positive }
\end{aligned}
$$

This demand data is available at the district level. We obtain subdistrict-level data by distributing this demand over the proportion of the population for a subdistrict obtained 
from census data, i.e., Census (2011) (Anparasan and Lejeune 2019). Next, data on the latitude and longitude of subdistricts are obtained from latlong.net. These latitudes and longitudes are used to calculate a distance matrix using the popular Haversine formula. The fixed and variable costs are assumed to be 14,000 and 4000 , respectively. The perunit transportation cost is assumed to be 20 , and the per-unit capacity cost is 1500 . As previously mentioned, the 58 subdistricts of the Pune division are considered potential facility locations as well as demand nodes. This data is also reported in Appendix Table 7.

\subsection{Results}

The proposed mathematical model is solved using CPLEX 12.10.0 optimization software. The solver returns optimal solutions for the datasets in a reasonable time. All computational experiments are conducted on an Intel (R) Core (TM) i5-10 ${ }^{\text {th }}$ GEN HP laptop with a $2.11 \mathrm{GHz}$ processor, $8 \mathrm{~GB}$ of RAM, and a Windows 10 64-bit operating system. The proposed model is evaluated using real data to demonstrate the model's applicability to real life during a pandemic outbreak such as COVID-19. Subdistrict-level data are obtained for the Pune division of Maharashtra, India. First, we analyze the value of the objective functions for various values of $P(P=1,2,3 \ldots .58)$. The results show that the value of the first objective function (the total cost) increases with $P$ (Fig. 1). The value of the second objective function, which aims to minimize the maximum travel time, decreases with increasing $P$.

We use $P=27$ as an example of how the TTLs should have been installed/located in the Pune division to ensure equity of services to all the subdistricts during COVID19. We also show how demand nodes/subdistricts should be assigned to TTLs and report the capacities of the TTLs needed to fulfil the demand of all subdistricts. These results are presented in Table 6 . The first column of Table 6 lists the 58 subdistricts of the Pune division. The second column shows whether a TTL has been opened in a subdistrict. The value of $y_{j}$ is 1 if a facility has been opened 1 and 0 otherwise. The third column contains the assignment of demand nodes to the TTLs. The fourth column presents the capacities of the TTLs opened at various locations. Finally, the fifth column shows that none of the TTLs have underutilized capacity. For $P=27$, the value of the first objective function, the total cost, is $6.08 \mathrm{E}+11$, and the value of the second objective function, the maximum travel time, is $30.681 \mathrm{~min}$ for a computational time of $180.31 \mathrm{~s}$. Figure 2 shows the TTL locations on a map of the Pune division. Subdistricts are labeled from 1 to 58 on the pictorial map, and details of all the subdistricts are given in Table 7 (Appendix).

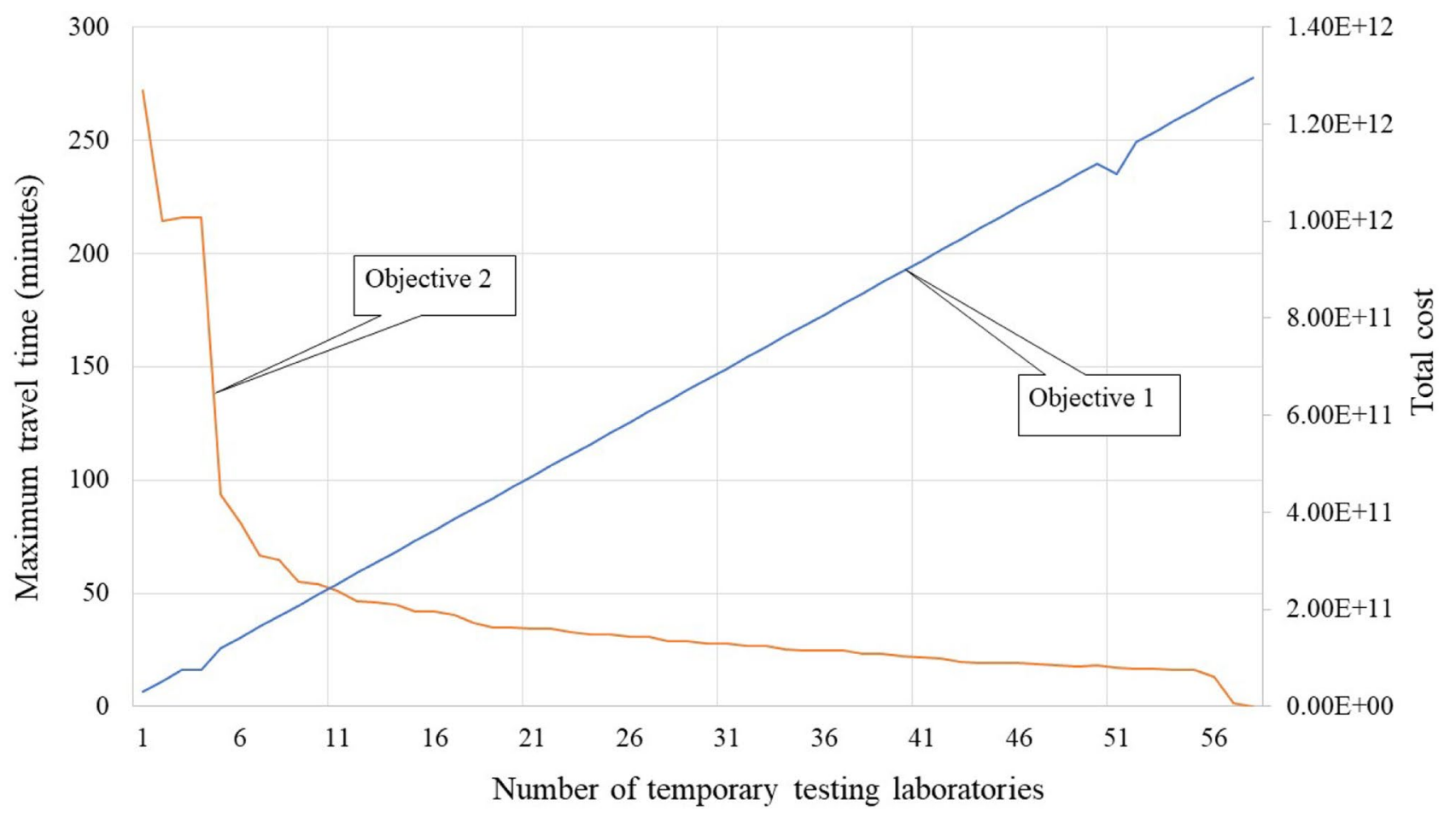

Fig. 1 Objective functions at the different number of opened facilities 
Table 6 Solutions referring to facility location, demand allocation and capacity

\begin{tabular}{|c|c|c|c|c|c|}
\hline $\mathrm{S} \mathrm{No}$ & Potential locations $(j)$ & $\begin{array}{l}\text { Opened } \\
\text { facility } \\
\left(\boldsymbol{y}_{\boldsymbol{j}}\right)\end{array}$ & $\begin{array}{l}\text { Assigned demand } \\
\text { points }\left(z_{i j}\right)\end{array}$ & $\begin{array}{l}\text { Capacity of } \\
\text { opened facility } \\
\left(\boldsymbol{S}_{j}\right)\end{array}$ & $\begin{array}{l}\text { Underutilized } \\
\text { capacity }\end{array}$ \\
\hline 1 & Junnar & 0 & 0 & 0 & 0 \\
\hline 2 & Ambegaon & 1 & 1,2 & 254,690 & 0 \\
\hline 3 & Shirur & 1 & 3 & 159,308 & 0 \\
\hline 4 & Khed & 1 & 4 & 188,387 & 0 \\
\hline 5 & Mawal & 0 & 0 & 0 & 0 \\
\hline 6 & Mulshi & 1 & $5,6,8,11$ & $1,597,354$ & 0 \\
\hline 7 & Haveli & 1 & 7 & $1,042,520$ & 0 \\
\hline 8 & Pune City & 0 & 0 & 0 & 0 \\
\hline 9 & Daund & 1 & 9 & 155,452 & 0 \\
\hline 10 & Purandhar & 1 & 10 & 94,963 & 0 \\
\hline 11 & Velhe & 0 & 0 & 0 & 0 \\
\hline 12 & Bhor & 0 & 0 & 0 & 0 \\
\hline 13 & Baramati & 1 & 13,18 & 227,321 & 0 \\
\hline 14 & Indapur & 1 & 14,32 & 210,853 & 0 \\
\hline 15 & Mahabaleshwar & 0 & 0 & 0 & 0 \\
\hline 16 & Wai & 1 & $12,15,16,17$ & 137,130 & 0 \\
\hline 17 & Khandala & 0 & 0 & 0 & 0 \\
\hline 18 & Phaltan & 0 & 0 & 0 & 0 \\
\hline 19 & Man & 0 & 0 & 0 & 0 \\
\hline 20 & Khatav & 1 & 19,20 & 76,333 & 0 \\
\hline 21 & Koregaon & 0 & 0 & 0 & 0 \\
\hline 22 & Satara & 1 & 21,22 & 115,744 & 0 \\
\hline 23 & Jaoli & 1 & 23 & 16,230 & 0 \\
\hline 24 & Patan & 1 & 24 & 45,642 & 0 \\
\hline 25 & Karad & 0 & 0 & 0 & 0 \\
\hline 26 & Karmala & 1 & 26 & 27,987 & 0 \\
\hline 27 & Madha & 1 & $27,28,30$ & 107,076 & 0 \\
\hline 28 & Barshi & 0 & 0 & 0 & 0 \\
\hline 29 & Solapur North & 1 & 29,35 & 144,970 & 0 \\
\hline 30 & Mohol & 0 & 0 & 0 & 0 \\
\hline 31 & Pandharpur & 1 & 31,34 & 71,295 & 0 \\
\hline 32 & Malshiras & 0 & 0 & 0 & 0 \\
\hline 33 & Sangole & 1 & 33,54 & 53,855 & 0 \\
\hline 34 & Mangalvedhe & 0 & 0 & 0 & 0 \\
\hline 35 & Solapur South & 0 & 0 & 0 & 0 \\
\hline 36 & Akkalkot & 1 & 36 & 34,594 & 0 \\
\hline 37 & Shahuwadi & 0 & 0 & 0 & 0 \\
\hline 38 & Panhala & 0 & 0 & 0 & 0 \\
\hline 39 & Hatkanangle & 1 & $39,40,41,44$ & 224,870 & 0 \\
\hline 40 & Shirol & 0 & 0 & 0 & 0 \\
\hline 41 & Karvir & 0 & 0 & 0 & 0 \\
\hline 42 & Bavda & 0 & 0 & 0 & 0 \\
\hline 43 & Radhanagari & 1 & $42,43,45$ & 34,542 & 0 \\
\hline 44 & Kagal & 0 & 0 & 0 & 0 \\
\hline 45 & Bhudargad & 0 & 0 & 0 & 0 \\
\hline 46 & Ajra & 1 & $46,48,47$ & 47,737 & 0 \\
\hline 47 & Gadhinglaj & 0 & 0 & 0 & 0 \\
\hline 48 & Chandgad & 0 & 0 & 0 & 0 \\
\hline 49 & Shirala & 1 & $37,38,49,50$ & 121,875 & 0 \\
\hline
\end{tabular}


Table 6 (continued)

\begin{tabular}{llllll}
\hline S No & Potential locations $(\boldsymbol{j})$ & $\begin{array}{l}\text { Opened } \\
\text { facility } \\
\left(\boldsymbol{y}_{\boldsymbol{j}}\right)\end{array}$ & $\begin{array}{l}\text { Assigned demand } \\
\text { points }\left(\boldsymbol{z}_{\boldsymbol{i}}\right)\end{array}$ & $\begin{array}{l}\text { Capacity of } \\
\text { opened facility } \\
\left(\boldsymbol{S}_{\boldsymbol{j}}\right)\end{array}$ & $\begin{array}{l}\text { Underutilized } \\
\text { capacity }\end{array}$ \\
\hline 50 & Walwa & 0 & 0 & 0 & 0 \\
51 & Palus & 0 & 0 & 0 & 0 \\
52 & Kadegaon & 1 & 25,52 & 107,965 & 0 \\
53 & Khanapur (Vita) & 0 & 0 & 0 & 0 \\
54 & Atpadi & 0 & 0 & 0 & 0 \\
55 & Tasgaon & 1 & $51,53,55,56,57$ & 211,193 & 0 \\
56 & Miraj & 0 & 0 & 0 & 0 \\
57 & Kavathemahankal & 0 & 0 & 0 & 0 \\
58 & Jat & 1 & 58 & 43,516 & 0 \\
\hline
\end{tabular}

\subsection{Discussion}

The aim of the present study is to provide guidance to health care supply chains during a pandemic outbreak by proposing a location-allocation model for the location of TTLs. The proposed model simultaneously minimizes the cost of facilities and ensures equity of services at all demand nodes. The model is first solved using Holmberg et al.'s (1999) benchmark instances, and the results show that the located TTLs suffer from capacity underutilization, resulting in resource wastage during critical times of a pandemic outbreak. Therefore, the model is updated to prevent capacity underutilization by introducing a variable to capture the capacity requirements of each TTL. The updated model is solved using the same benchmark instances, and the results show that the updated model can ensure no capacity underutilization. Finally, a case study of the Pune division of Maharashtra is utilized to demonstrate the model's applicability to real life.

The results show a linear relationship between the number of facilities opened and the total cost (Fig. 1). That is, the number of facilities to be opened increases the value of objective function 1, which increases the total cost. Each new facility opening adds a fixed cost to the objective
Fig. 2 Temporary testing laboratories locations at sub-districts across Pune division

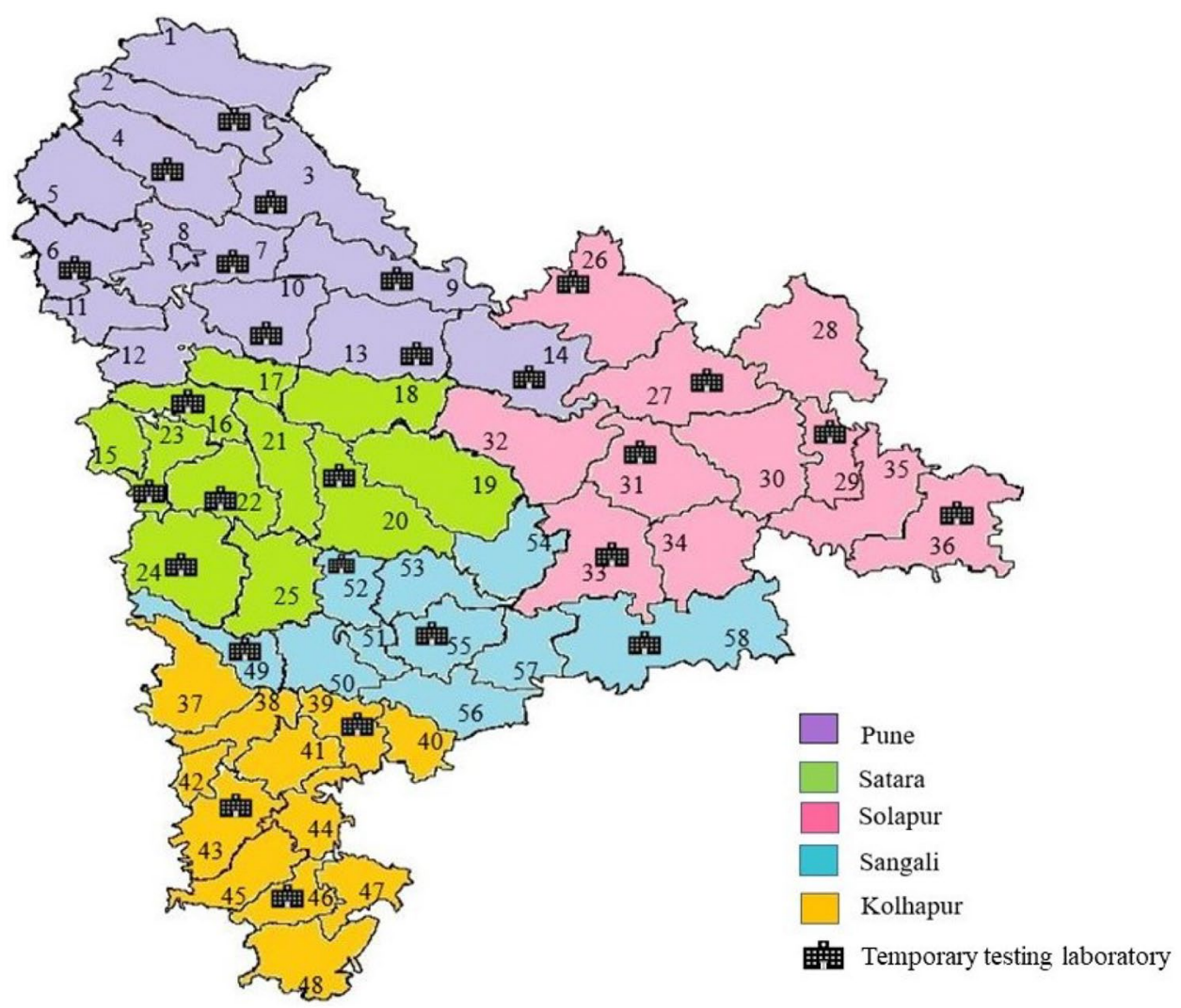


function (Eq. 10). By contrast, the operating and capacity costs remain constant, because these costs depend on demand and are independent of the number of facilities to be opened $P$. The transportation cost decreases with increasing $P$, because placing facilities closer to demand nodes reduces the travel time. However, the transportation cost is smaller than the fixed cost of opening a facility, which is in line with results in the literature (Amiri et al. 2019). Hence, the total cost of establishing TTLs increases with $P$.

The study findings show that the maximum travel time is a negative exponential function in the number of facilities to be opened $P$ (Fig. 1). The maximum travel time decreases suddenly from $P=1$ to $P=5$ and decreases gradually beyond $P=5$. The maximum travel time changes marginally beyond $P=14$. This finding is in line with Risanger et al.'s report (2021) that an increase in test pharmacies reduces the transportation distance and increases access to COVID19 testing. The results of the present study can be used to determine the trade-off between the proposed objective functions (Fig. 1). For example, a short transportation time for test sample delivery is important (Koshta et al. 2021). However, decision-makers/policy-makers may not be interested in marginal changes in the delivery time after a certain number of facilities are opened because limited resources and finances are available for multiple tasks (Queiroz et al. 2020).
Finally, for the instance $P=27$, the highest number of TTLs are opened in Pune district, followed by Solapur, Satara, Sangali, and Kolhapur districts (Fig. 2). We also find that the TTL opened at Tasgaon is assigned the highest number of subdistricts. These subdistricts include Palus, Khanapur (Vita), Tasgaon, Miraj, and Kavathemahankal. Furthermore, four TTLs are assigned four subdistricts, three TTLs are assigned three subdistricts, nine TTLs are assigned two subdistricts, and ten TTLs are only assigned to themselves. The capacity determination results show that the TTL opened at Mulshi has the highest capacity of 1,597,354 units, whereas the TTL opened at Jaoli has the lowest capacity of 16,230 units.

\subsection{Sensitivity analysis}

The number of TTLs to be opened $P$ and the per-unit transportation cost $M$ are the most critical factors in the proposed model. Hence, the impact of these factors on the model output is assessed in this section, and the results are reported in Fig. 3. Different values of the transportation cost $M$ are considered under four scenarios of $P=30 \%, 40 \%, 60 \%$, and $70 \%$ to assess the change in the model output. For all four scenarios, there is a linear relationship between the transportation cost and the value of objective function 1 (Fig. 3). For $P=30 \%$, a 100-unit increase in the per-unit transportation cost results in an average $0.00268 \%$ increase in the total
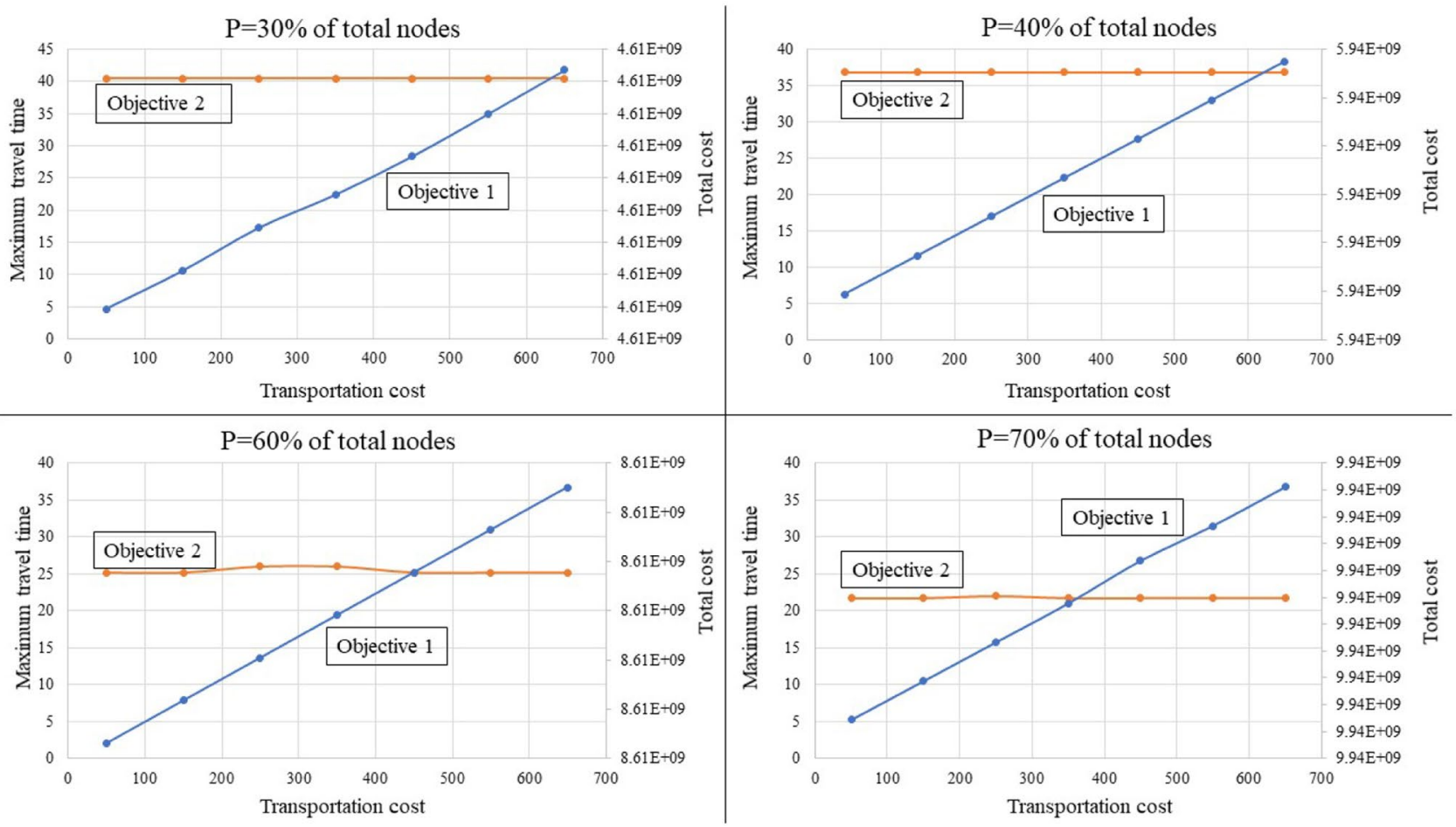

Fig. 3 Results of sensitivity analysis for the change in model output under different values of transportation cost $M$ and number of TTLs $P$ 
cost. However, for $P=70 \%$, the percentage increase in the total cost decreases to $0.000291 \%$ per 100 -unit increase in the per-unit transportation cost. As $P$ increases from 30 to $40 \%$, the total cost increases by $28 \%$. The total cost increases by $44 \%$ as $P$ increases from 40 to $60 \%$ and by $15 \%$ as $P$ rises from 60 to $70 \%$. Increasing $P$ from 30 to $70 \%$ causes the total cost to increase by $115 \%$, maintaining the transportation cost constant. Finally, as $P$ increases from 30 to $70 \%$, the maximum travel time decreases from $40.44 \mathrm{~min}$ to $21.77 \mathrm{~min}$, corresponding to a reduction of almost $50 \%$ in the maximum travel time.

\section{Study implications}

This study has three major implications for practice. The proposed model can provide guidance to decision-makers and government health authorities on improving the health care system during a pandemic. First, motivated by the current scenario in which countries are struggling to reduce the spread of the COVID-19 pandemic, we propose a mathematical model for the location of temporary testing laboratories (TTLs) to enable the timely identification and isolation of infected individuals. The model can be used to make decisions on the location of TTLs and the assignment of demand nodes (susceptible individuals in pandemic outbreaks) to these facilities.

Second, the initial/first model is characterized by capacity underutilization or nonoperating costs, and the model results show that capacity underutilization can lead to inefficient use of available/allocated funds. The updated model can enable policy- and decision-makers to evaluate/determine the capacity of located facilities. This capacity determination can prevent underutilization of located facilities, thus minimizing resource wastage. Exactly one assignment is considered in the model to ensure that the nearest TTL fulfils the demand of all the nodes in a timely manner.

Third, policy- and decision-makers could use the proposed model to ensure equity of services at all demand nodes. That is, the aim of the objective function, the minimization of the maximum travel time, is to reduce the distance between any demand node and a TTL location. This unique feature is important because services may be delayed to demand nodes that are far from TTLs near populated zones or a cluster of other demand nodes. As a result, the number of infected cases at the isolated demand nodes may increase and infection may thereby spread to nearby nodes, preventing the realization of a virus-free society. However, the proposed model ensures equity of services, i.e., the TTLs are located to ensure no demand nodes are far from a TTL.

\section{Conclusion and future research avenues}

The contagious nature of COVID-19 has caused immense human suffering. As a result, timely testing is crucial to suppress pandemic spread to reduce suffering. We propose that timely testing could be achieved by reducing the logistics/ transportation time of test samples from sample collection centers to temporary testing laboratories (TTLs). A biobjective mixed-integer linear programming model is proposed for the location of TTLs at the subdistrict level. An objective function is proposed to minimize the total cost of establishing and operating TTLs. The cost of transporting test samples from a demand node to a TTL and capacity underutilization costs are included in the total cost. A second objective function is proposed to minimize the maximum travel time from a demand node to a TTL to ensure equity of services at all demand nodes. The model can be used to determine the capacity of opened TTLs to prevent capacity underutilization. Finally, the model is tested for a case study in Maharashtra, India.

Scholars could explore several further research directions. First, the proposed model could be extended to determine the location of sample collection centers and TTLs simultaneously. For this purpose, ward-village level data should be used to ensure that the sample collection centers are located near people for ease and convenience of action. Second, researchers should determine other factors that negatively impact test samples' logistics and work toward eliminating these barriers. Finally, scholars have increasingly been suggesting that the implementation of Industry 4.0 technologies, such as the Internet of Things, big data, and artificial intelligence, could substantially enhance the resilience of supply chains (Kumar et al. 2021). The implications of using Industry 4.0 technologies in health care supply chains to facilitate timely sample testing could be explored in future studies.

\section{Appendix}


Table 7 Districts/Sub-districts details of Pune division

\begin{tabular}{|c|c|c|c|c|c|c|}
\hline S.No & District & Sub-district & Longitude & Latitude & $\begin{array}{l}\text { Cumulative } \\
\text { Infected } \\
\text { case }\end{array}$ & $\begin{array}{l}\text { Demand (number of } \\
\text { susceptible individuals) }\end{array}$ \\
\hline 1 & \multirow[t]{14}{*}{ Pune } & Junnar & 19.2113 & 73.8734 & 24,040 & 160,265 \\
\hline 2 & & Ambegaon & 19.1166 & 73.7306 & 14,164 & 94,425 \\
\hline 3 & & Shirur & 18.8309 & 74.3733 & 23,897 & 159,308 \\
\hline 4 & & Khed (pn) & 18.8608 & 73.8844 & 28,258 & 188,387 \\
\hline 5 & & Mawal & 18.7464 & 73.6372 & 23,580 & 157,198 \\
\hline 6 & & Mulshi & 18.5245 & 73.6153 & 10,698 & 71,320 \\
\hline 7 & & Haveli & 19.7515 & 75.7139 & 156,378 & $1,042,520$ \\
\hline 8 & & Pune City & 18.5167 & 73.8542 & 202,058 & $1,347,053$ \\
\hline 9 & & Daund & 18.4666 & 74.5793 & 23,318 & 155,452 \\
\hline 10 & & Purandhar & 18.3447 & 74.0317 & 14,244 & 94,963 \\
\hline 11 & & Velhe & 18.3004 & 73.6372 & 3267 & 21,783 \\
\hline 12 & & Bhor & 18.1563 & 73.8432 & 11,186 & 74,571 \\
\hline 13 & & Baramati & 18.1537 & 74.5711 & 26,265 & 175,102 \\
\hline 14 & & Indapur & 18.1171 & 75.0239 & 23,616 & 157,446 \\
\hline 15 & \multirow[t]{11}{*}{ Satara } & Mahabaleshwar & 17.9248 & 73.658 & 1665 & 11,099 \\
\hline 16 & & Wai & 17.9523 & 73.8914 & 4578 & 30,519 \\
\hline 17 & & Khandala & 18.0586 & 74.0148 & 3141 & 20,941 \\
\hline 18 & & Phaltan & 17.9911 & 74.4298 & 7833 & 52,219 \\
\hline 19 & & Man & 17.7027 & 74.5418 & 5158 & 34,384 \\
\hline 20 & & Khatav & 17.6627 & 74.3658 & 6292 & 41,949 \\
\hline 21 & & Koregaon & 17.7007 & 74.158 & 5886 & 39,240 \\
\hline 22 & & Satara & 17.6884 & 74.0042 & 11,476 & 76,504 \\
\hline 23 & & Jaoli & 17.9 & 76.4 & 2435 & 16,230 \\
\hline 24 & & Patan & 17.3772 & 73.9007 & 6846 & 45,642 \\
\hline 25 & & Karad & 17.2859 & 74.1823 & 13,351 & 89,009 \\
\hline 26 & \multirow[t]{11}{*}{ Solapur } & Karmala & 18.408 & 75.1912 & 4198 & 27,987 \\
\hline 27 & & Madha & 18.0342 & 75.5163 & 5345 & 35,634 \\
\hline 28 & & Barshi & 18.2359 & 75.6876 & 6148 & 40,988 \\
\hline 29 & & Solapur North & 17.6717 & 75.8975 & 17,442 & 116,279 \\
\hline 30 & & Mohol & 17.8093 & 75.6443 & 4568 & 30,454 \\
\hline 31 & & Pandharpur & 17.6787 & 75.3333 & 7297 & 48,648 \\
\hline 32 & & Malshiras & 17.8637 & 74.9091 & 8011 & 53,407 \\
\hline 33 & & Sangole & 17.4368 & 75.1928 & 5326 & 35,504 \\
\hline 34 & & Mangalvedhe & 17.5131 & 75.4489 & 3397 & 22,647 \\
\hline 35 & & Solapur South & 17.6599 & 75.9063 & 4304 & 28,691 \\
\hline 36 & & Akkalkot & 17.5269 & 76.206 & 5189 & 34,594 \\
\hline 37 & \multirow[t]{12}{*}{ Kolhapur } & Shahuwadi & 16.9189 & 73.9332 & 2493 & 16,621 \\
\hline 38 & & Panhala & 16.8069 & 74.1125 & 3484 & 23,224 \\
\hline 39 & & Hatkanangle & 16.7459 & 74.4268 & 10,846 & 72,313 \\
\hline 40 & & Shirol & 16.7339 & 74.6022 & 5250 & 35,005 \\
\hline 41 & & Karvir & 16.6954 & 74.2246 & 13,935 & 92,900 \\
\hline 42 & & Bavda & 16.5442 & 73.8284 & 480 & 3202 \\
\hline 43 & & Radhanagari & 16.4114 & 73.9964 & 2682 & 17,879 \\
\hline 44 & & Kagal & 16.5752 & 74.3156 & 3698 & 24,652 \\
\hline 45 & & Bhudargad & 16.316 & 74.1443 & 2019 & 13,461 \\
\hline 46 & & Ajra & 16.1162 & 74.21 & 1615 & 10,767 \\
\hline 47 & & Gadhinglaj & 16.2242 & 74.3515 & 3031 & 20,209 \\
\hline 48 & & Chandgad & 15.9413 & 74.1826 & 2514 & 16,761 \\
\hline 49 & Sangali & Shirala & 16.9846 & 74.1261 & 3239 & 21,592 \\
\hline
\end{tabular}


Table 7 (continued)

\begin{tabular}{|c|c|c|c|c|c|c|}
\hline S.No & District & Sub-district & Longitude & Latitude & $\begin{array}{l}\text { Cumulative } \\
\text { Infected } \\
\text { case }\end{array}$ & $\begin{array}{l}\text { Demand (number of } \\
\text { susceptible individuals) }\end{array}$ \\
\hline 50 & & Walwa & 17.0505 & 74.2661 & 9066 & 60,438 \\
\hline 51 & & Palus & 17.0958 & 74.4518 & 3278 & 21,857 \\
\hline 52 & & Kadegaon & 17.2985 & 74.3321 & 2843 & 18,956 \\
\hline 53 & & Khanapur (Vita) & 17.2616 & 74.7151 & 3384 & 22,560 \\
\hline 54 & & Atpadi & 17.4232 & 74.939 & 2753 & 18,351 \\
\hline 55 & & Tasgaon & 17.0377 & 74.6025 & 4998 & 33,321 \\
\hline 56 & & Miraj & 16.8505 & 74.5949 & 16,989 & 113,266 \\
\hline 57 & & Kavathemahankal & 17.0052 & 74.8613 & 3028 & 20,189 \\
\hline 58 & & Jat & 17.0492 & 75.2179 & 6527 & 43,516 \\
\hline
\end{tabular}

Sources: Public Health Department, Government of Maharashtra; LatLong.net

\section{References}

Aldrighetti R, Battini D, Ivanov D, Zennaro I (2021) Costs of resilience and disruptions in supply chain network design models: a review and future research directions. Int J Prod Econ 235:108103. https://doi.org/10.1016/j.ijpe.2021.108103

Amiri M, Amin SH, Tavakkoli-Moghaddam R (2019) A Lagrangean decomposition approach for a novel two-echelon node-based location-routing problem in an offshore oil and gas supply chain. Transportation Research Part E: Logistics and Transportation Review 128:96-114. https://doi.org/10.1016/j.tre.2019.05.014

Anparasan A, Lejeune M (2019) Resource deployment and donation allocation for epidemic outbreaks. Ann Oper Res 283(1):9-32. https://doi.org/10.1007/s10479-016-2392-0

Araz OM, Ramirez-Nafarrate A, Jehn M, Wilson FA (2020) The importance of widespread testing for COVID-19 pandemic: systems thinking for drive-through testing sites. Health Systems 9(2):119123. https://doi.org/10.1080/20476965.2020.1758000

Banerjee S (2018) 17.51 lakh students to sit for SSC exams in Maharashtra today. The Hindu. https://www.thehindu.com/news/national/ other-states/1751-lakh-students-to-sit-for-ssc-exams-in-maharashtratoday/article22883593.ece

Baz JE, Ruel S (2021) Can supply chain risk management practices mitigate the disruption impacts on supply chains' resilience and robustness? Evidence from an empirical survey in a COVID-19 outbreak era. Int J Prod Econ 233:107972. https://doi.org/10. 1016/j.ijpe.2020.107972

Beheshtifar S, Alimoahmmadi A (2015) A multi-objective optimisation approach for location-allocation of clinics. Int Trans Oper Res 22(2):313-328. https://doi.org/10.1111/itor.12088

Blackmon L, Chan R, Carbral O, Chintapally G, Dhara S, Felix P, Wu W (2021) Rapid Development of a Decision Support System to Alleviate Food Insecurity at the Los Angeles Regional Food Bank Amid the Covid-19 Pandemic. Prod Oper Manag 1-17. https:// doi.org/10.1111/poms.13365

Büyüktahtakın E, Des-Bordes E, Kıbış EY (2018) A new epidemicslogistics model: Insights into controlling the Ebola virus disease in West Africa. Eur J Oper Res 265(3):1046-1063. https://doi.org/ 10.1016/j.ejor.2017.08.037

Census (2011) Maharashtra Population 2011-2021. In: Office of the Registrar General \& Census Commissioner, India. https://www. census2011.co.in/census/state/maharashtra.html. Accessed 6 April 2021

Chakraborty I, Maity P (2020) COVID-19 outbreak: Migration, effects on society, global environment and prevention. Sci Total Environ 728:138882. https://doi.org/10.1016/j.scitotenv.2020.138882
Chowdhury S, Emelogu A, Marufuzzaman M, Nurre SG, Bian L (2017) Drones for disaster response and relief operations: A continuous approximation model. Int J Prod Econ 188:167-184. https://doi.org/10.1016/j.ijpe.2017.03.024

Chowdhury MT, Sarkar A, Paul SK, Moktadir MA (2020) A case study on strategies to deal with the impacts of COVID-19 pandemic in the food and beverage industry. Oper Manag Res 1-13. https://doi. org/10.1007/s12063-020-00166-9

Ekici A, Keskinocak P, Swann JL (2014) Modeling influenza pandemic and planning food distribution. Manuf Serv Oper Manag 16(1):11-27. https://doi.org/10.1287/msom.2013.0460

Holmberg K, Rönnqvist M, Yuan D (1999) An exact algorithm for the capacitated facility location problems with single sourcing. Eur J Oper Res 113(3):544-559. https://doi.org/10.1016/S03772217(98)00008-3

IndiaNetZone (2017). Districts of Pune division, Maharashtra. https:// www.indianetzone.com/79/districts_pune_division.htm. Accessed 16 April 2021

Ivanov D (2021) Supply chain viability and the COVID-19 pandemic: A conceptual and formal generalisation of four major adaptation strategies. Int J Prod Res 59(12):1-18. https://doi.org/10.1080/ 00207543.2021 .1890852

Ivanov D, Dolgui A (2021a) OR-methods for coping with the ripple effect in supply chains during COVID-19 pandemic: Managerial insights and research implications. Int J Prod Econ 232:107921. https://doi.org/10.1016/j.ijpe.2020.107921

Ivanov D, Dolgui A (2021b) Stress testing supply chains and creating viable ecosystems. Oper Manag Res 1-12. https://doi.org/10. 1007/s12063-021-00194-z

Kodge BG (2021) A review on current status of COVID19 cases in Maharashtra state of India using GIS: a case study. Spat Inf Res 29(2):223-229. https://doi.org/10.1007/s41324-020-00349-3

Koshta N, Devi Y, Patra S (2021) Aerial Bots in the Supply Chain: A New Ally to Combat COVID-19. Technol Soc 66:101646. https:// doi.org/10.1016/j.techsoc.2021.101646

Kumar S (2020) Predication of pandemic COVID-19 situation in Maharashtra. India Medrxiv. https://doi.org/10.1101/2020.04. 10.20056697

Kumar P, Singh RK, Kumar V (2021) Managing supply chains for sustainable operations in the era of industry 4.0 and circular economy: Analysis of barriers. Resour Conserv Recycl 164:105215. https://doi.org/10.1016/j.resconrec.2020.105215

Lam EHY, Cowling BJ, Cook AR, Wong JYT, Lau MSY, Nishiura H (2011) The feasibility of age-specific travel restrictions during influenza pandemics. Theor Biol Med Model 8(1):44. https://doi. org/10.1186/1742-4682-8-44 
Lee EK, Smalley HK, Zhang Y, Pietz F, Benecke B (2009) Facility location and multi-modality mass dispensing strategies and emergency response for biodefence and infectious disease outbreaks. International Journal of Risk Assessment and Management 12(24):311-351. https://doi.org/10.1504/ijram.2009.025925

Liu M, Xu X, Cao J, Zhang D (2020) Integrated planning for public health emergencies: A modified model for controlling H1N1 pandemic. Journal of the Operational Research Society 71(5):748761. https://doi.org/10.1080/01605682.2019.1582589

Mangili A, Gendreau MA (2005) Transmission of infectious diseases during commercial air travel. Lancet 365(9463):989-996. https:// doi.org/10.1016/S0140-6736(05)71089-8

Meghana A, Aparna Y, Chandra SM, Sanjeev S (2021) Emergency preparedness and response (EP\&R) by pharmacy professionals in India: Lessons from the COVID-19 pandemic and the way forward. Res Social Adm Pharm 17(1):2018-2022. https://doi.org/ 10.1016/j.sapharm.2020.04.028

Nasrabadi M, A, Najafi M, Zolfagharinia H, (2020) Considering shortterm and long-term uncertainties in location and capacity planning of public healthcare facilities. Eur J Oper Res 281(1):152-173. https://doi.org/10.1016/j.ejor.2019.08.014

Núñez Ares J, de Vries H, Huisman D (2016) A column generation approach for locating roadside clinics in Africa based on effectiveness and equity. Eur J Oper Res 254(3):1002-1016. https://doi. org/10.1016/j.ejor.2016.04.031

Oeser G, Romano P (2021) Exploring risk pooling in hospitals to reduce demand and lead time uncertainty. Oper Manag Res 14(1):78-94. https://doi.org/10.1007/s12063-020-00171-y

Paul SK, Chowdhury P (2020) A production recovery plan in manufacturing supply chains for a high-demand item during COVID-19. Int J Phys Distrib Logist Manag 51(2):104-125. https://doi.org/ 10.1108/IJPDLM-04-2020-0127

Qin X, Godil DI, Khan MK, Sarwat S, Alam S, Janjua L (2021) Investigating the effects of COVID-19 and public health expenditure on global supply chain operations: an empirical study. Oper Manag Res 1-13. https://doi.org/10.1007/s12063-020-00177-6

Queiroz MM, Ivanov D, Dolgui A, Wamba SF (2020) Impacts of epidemic outbreaks on supply chains: mapping a research agenda amid the COVID-19 pandemic through a structured literature review. Ann Oper Res 1-38. https://doi.org/10.1007/ s10479-020-03685-7

Radhakrishnan V, Sen S, Singaravelu N (2020) Data: Why has Mumbai seen the most coronavirus cases in Maharashtra? The Hindu. https://www.thehindu.com/data/data-why-mumbai-has-seen-themost-coronavirus-cases-in-maharashtra/article31334926.ece. Accessed 16 January 2021
Risanger S, Singh B, Morton D, Meyers LA (2021) Selecting pharmacies for COVID-19 testing to ensure access. Health Care Manag Sci 24:330-338. https://doi.org/10.1007/s10729-020-09538-w

Rodríguez-Espíndola O, Albores P, Brewster C (2018) Disaster preparedness in humanitarian logistics: A collaborative approach for resource management in floods. Eur J Oper Res 264(3):978-993. https://doi.org/10.1016/j.ejor.2017.01.021

Salathé M, Christian AL, Richard N, Silvia S, Emma H, Jacques F, Marcel Z, Gabriela S, Manuel B, Annelies WS, Isabella E, Matthias E, Nicola L (2020) COVID-19 epidemic in Switzerland: On the importance of testing, contact tracing and isolation. Swiss Med Wkly 150(1112). https://doi.org/10.4414/smw.2020.20225

Sinha A (2021) Pune scales a new peak, detects 9,126 Covid-19 cases in a day. Indian Express. https://indianexpress.com/article/cities/ pune/pune-covid-19-cases-update-mahar ashtra-7256669/. Accessed 20 January 2021.

Sodhi MS, Tang CS, Willenson ET (2021) Research Opportunities in Preparing Supply Chains of Essential Goods for Future Pandemics. Int J Prod Res 1-16. https://doi.org/10.1080/00207543.2021. 1884310

Sun L, Depuy GW, Evans GW (2014) Multi-objective optimisation models for patient allocation during a pandemic influenza outbreak. Comput Oper Res 51:350-359. https://doi.org/10.1016/j. cor.2013.12.001

Tanne JH, Hayasaki E, Zastrow M, Pulla P, Smith P, Rada AG (2020) Covid-19: How doctors and healthcare systems are tackling coronavirus worldwide. The BMJ 368. https://doi.org/10.1136/bmj. m1090

Tirkolaee EB, Abbasian P, Weber GW (2021) Sustainable fuzzy multitrip location-routing problem for medical waste management during the COVID-19 outbreak. Sci Total Environ 756:143607. https://doi.org/10.1016/j.scitotenv.2020.143607

WHO (2020) Critical Preparedness, Readiness and Response Actions for COVID-19: Interim Guidance. In: World Health Organization. https://apps.who.int/iris/bitstream/handle/10665/331511/ CriticalpreparednessreadinessandresponseactionsCOVID102020-03-22_FINALeng.pdf? sequence $=1 \&$ is Allowed $=y$. Accessed 6 November 2020

Zeferino EFS, Makinde OA, Mpofu K, Ramatsetse BI, Daniyan IA (2021) Prioritising factors influencing the selection of a suitable quarantine facility for COVID-19 patients using Pareto-enhanced analytical hierarchy process. Facilities 39(7-8):488-507. https:// doi.org/10.1108/F-04-2020-0043

Publisher's Note Springer Nature remains neutral with regard to jurisdictional claims in published maps and institutional affiliations. 